20 Levitas A, Hagerman RJ, Braden M, Rimland B, McBogg P, Matus I. Autism and the fragile X syndrome. Developmental and Behavioural Pediatrics 1983;4:151-8.

21 Goldfine PE, McPherson PM, Heath GA, Hardesty VA, Beauregard LJ, Gordon B. Association of fragile X syndrome with autism. Am f Psychiairy 1985;142:108-10.

22 Kinnell HG. Fragile X disorder associated with antisocial personality. Lancet 1982;ii: 1104.

23 Popovich B, Vekemans M, Rosenblatt D, Monroe P. Fragile X. N Engl f Med 1982;306:1551-2.

24 Webb GC, Rogers JG, Pitt DB, Halliday J, Theobald T. Transmission of fragile (X) (q27) site from a male. Lancet $1981 ;$ ii: $1231-2$.

25 Turner G, Brookwell R, Daniel A, Selikowitz M, Zilibowitz $M$. Heterozygous expression of $\mathrm{X}$-linked mental retardation and the marker X: fra (x) (q27). N Engl f Med 1980;303:662-4.

26 De La Cruz FF. Fragile X syndrome. Am $\mathcal{J}$ Ment Defic 1986;90:121.

27 Tommerup N, Sondergaard F, Tonnesen T, Kristensen M, Arveiler B, Schinzel A. First Tommerup N, Sondergaard F, Tonnesen T, Kristensen M, Arveiler B,

28 Gardner AP, Howell RT, McDermott A. Fragile X chromosome: consistent demonstration of fragile site in fibroblast cultures. Lancet 1982;i:101.

29 Rocchi M, Pecile V, Archidiacono N, Monni G, Dumez Y, Filippi G. Prenatal diagnosis of the fragile- $\mathrm{X}$ in male monozygotic twins: discordant expression of the fragile site in amniocytes. Prenat Diagn 1985;5:220-31.

30 Webb T, Butler D, Insley J, Weaver JB, Green S, Rodeck C. Prenatal diagnosis of Martin-Bel syndrome associated with fragile site of Xq27-28. Lancet 1981;ii:1423.

31 Webb T, Bunde S, Thake A, Todd J. Population incidence and segregation ratios in the MartinBell syndrome. Am $\mathcal{J}$ Med Genet 1986;23:573-80.

\section{When should patients be referred for liver transplantation?}

Liver transplantation is being used increasingly for patients with liver disease. In Europe in 1982 fewer than 100 transplants were performed, whereas in 1986 the number was about 450, 130 of them in Britain. The results are such that even two years ago Starzl, the pioneer of the procedure, was quoting actuarial five year survival rates of over $60 \% .^{1}$ But, though the indications are now well recognised, ${ }^{23}$ the problem remains as to when liver transplantation should be done.

Three years ago a National Institutes of Health consensus conference concluded that "an ideally timed transplantation procedure would be in a late enough phase of the disease to offer the patient no opportunity for spontaneous stabilisation or recovery, but in an early enough phase to give the surgical procedure a fair chance of success." " Liver transplantation is usually performed when the prognosis, with conventional treatment, is one year of life or when the symptoms are intolerable. Nevertheless, inherent in the consensus conference's statement is the unproved assumption that both the prognostic factors for survival and the factors that adversely affect surgery can be identified for the individual patient. What guidance, therefore, can we give the physician on when adults should be referred to a transplant centre?

The absolute contraindications to transplantation are few and easy to identify: advanced cardiac and pulmonary disease, active biliary sepsis, continued excess alcohol consumption, and, for almost all centres, extrahepatic spread of primary liver tumour or the presence of metastases in the liver. ${ }^{5}$ Less clear cut is age since many centres have done successful transplants in patients of over 60 . Previous upper abdominal surgery is often considered a relative contraindication; although, especially when portal hypertension is present, adhesions do add considerably to the difficulties, no study has shown that previous laparotomy adversely affects survival. ${ }^{67}$ The presence of a blocked portal vein is no longer considered to be a contraindication to grafting. In patients with replicating hepatitis $B$ virus the virus will probably infect the graft, ${ }^{89}$ but even if this occurs the quality of life after surgery may be excellent for some years. (The advent of newer techniques to prevent reinfection or treat chronic infection may make this less of a problem.) Evidence that the non-A non-B viruses affect the grafted liver is conflicting. ${ }^{10-12}$

Those causes of fulminant hepatic failure associated with a poor prognosis (such as non-A non-B viral hepatitis, fulminant Budd-Chiari syndrome, or drug sensitivity) are now further indications for transplantation. Potential candidates must be transferred to the transplant unit early: not only is there a short time span between the certainty that the prognosis is poor without transplantation and the onset of irreversible neurological damage, but also transferring a patient with encephalopathy carries increased risk of cerebral oedema and irreversible cerebral damage. ${ }^{13}$

Patients with hepatic malignancy should be referred for transplantation as soon as the presence of a non-resectable primary liver tumour confined to the liver is established. (It is appreciated that preoperative imaging will miss a proportion of extrahepatic metastases and that recurrence of the disease remains a considerable problem. ${ }^{14}$ ) Diagnostic biopsy of the tumour carries the potential risk of dissemination, but the need to confirm that the tumour is both malignant and primary usually outweighs these risks.

In patients with chronic parenchymal disease assessment of prognosis remains a problem. Prognostic models have been developed for both primary biliary cirrhosis ${ }^{15}$ and chronic active hepatitis, ${ }^{16}$ but, though these have been validated for populations, they are of less value for the individual. As the disease progresses nutrition becomes increasingly poor and poses an added risk. ${ }^{17}$ Given that rapid correction carries the risk of myelinolysis, hyponatraemia adds another risk to the procedure. ${ }^{18} \mathrm{~A}$ raised serum creatinine concentration has been suggested as a risk factor, ${ }^{6}$ but whether preoperative correction by, for example, dialysis improves the risk is to be shown.

Even if risk factors could be readily estimated, however, ethical considerations demand that patients with a limited prognosis without transplantation should not be denied operation merely because they are bad risks. As soon as a liver transplant becomes a possibility, therefore, they should be referred to a transplant centre. Not only can the patients be assessed by the physicians, surgeons, anaesthetists, nurses, and the other supporting staff concerned but they can also assess the liver transplant centre and discuss the procedure and its long term sequels with patients who have undergone it. If the transplant team consider that a patient is referred too early, then he or she should be followed up by the referring physician, possibly with occasional reassessment at the transplant centre.

Optimum management of the potential candidates demands close liaison between the local hospital and the transplant unit. Confidence must exist between both parties: confidence by the referring physician that his patient will not be precipitated too early into hazardous surgery and confidence by the transplant team that it will not be called on to perform "miracles" in moribund patients.

JAMES NEUBERGER

Consultant Physician,

Liver Unit,

Queen Elizabeth Hospital,

Birmingham B15 2TH

\footnotetext{
Starzl TE, Iwatsuki S, Shaw BW, Gordon RD. Orthotopic liver transplantation in 1984

Transplant Proc 1985;17:250-8.
2 Gordon RD, Shaw BW, Iwatsuki S, Esquivel CO, Starzl TE. Indications for liver transplantation in the cyclosporin era. Surgical Clin North Am 1986;66:541-56.

3 Calne RY, Williams R, Rolles K. Liver transplantation in the adult. World f Surg 1986;10:422-31.

4 National Institute of Health. Consensus development conference statement. Hepatology 1984;4:107S-10S.

5 Margreiter $R$. Indications for liver transplantation for primary and secondary liver tumour. Transplant Proc 1986;18:74-7.

6 Mons VE, Millan I, Gavaler J, Starzl TE, Van Thiel DH. Prognostic value of pre-operatively obtained clinical and laboratory data in predicting survival following orthotopic live transplantation. Hepatology 1986;6:922-7.

7 de Silva ABG, Gore SM, White DJG, Bourgeon A, Rolles K, Calne RY. Analysis of risk factors in liver transplantation. Transplant Proc 1986;18:1210-2.
} 
8 Lauchart W, Muller R, Pichlmayr R. Immunoprophylaxis of hepatitis B virus re-infection in recipient of human liver allograft. Transplant Proc 1987;19:2387-9.

9 Demetris AJ, Jaffe R, Sheahan DG, et al. Recurrent hepatitis B in liver allograft recipients. Am $\mathcal{F}$ Pathol 1986;125:161-72.

10 Adams D, Kirby R, Clements D, Elias E, McMaster P. Fulminant hepatic failure treated by transplantation. Lancet 1986;ii: 1037.

11 O'Grady J, Williams R, Calne RY. Transplantation in fulminant hepatic failure. Lancet 1986;ii:1227.

12 Wall WJ, Duff JH, Ghent CN, Stiller CR, Keown PA, Kutt LJ. Liver transplantation: the initial experience of a Canadian centre. Can 7 Surg 1985;28:286-9.

13 Canalese J, Gimson AES, Davis $M$, Williams $R$. Factors contributing to mortality in fulminant hepatic failure. BrMed f 1981;282:199-201.

14 Mittal R, Kowal L, Starzl TE, et al. Accuracy of computerised tomography in determining hepatic tumour size in patients receiving liver transplantation or resection. $f$ Clin Oncol 1984;2:637-42. tumour size in patients receiving liver transplantation or resection. $\mathcal{F}$ Clin Oncol 1984;2:637-42.
Christiensen $\mathrm{C}$, Neuberger J, Crowe J et al. Beneficial effect of azathioprine and prediction of prognosis in primary biliary cirrhosis. Gastroenterology 1985;89:1084-9.

16 Christiensen NE, Schlichting P, Andersen PK, et al. Updating prognosis and therapeutic evaluation in cirrhosis with Cox's multiple regression model in time dependent analysis. Scand $\mathcal{J}$ Gastroenterol 1986;21:163-74.

17 Hehir DJ, Jenkins RL, Bistrian BR, Blackburn GL. Nutrition in patients undergoing orthotopic liver transplantation. Foumal of Parenteral and Enteral Nutrition 1985;9:695-700.

18 McMaster P. Liver transplantation: results and problems. Currrent Opinions in Gastroenterology 1987;3:408-11.

\section{Migration and health}

Over the past 30 years at least 15 million people have migrated to northern Europe to help meet the labour demand of expanding national economies. Whereas Britain mainly recruited from her former colonies-initially the West Indies, then the Indian subcontinent-other countries, most notably Germany and France-attracted "guest workers" from southern Europe and north Africa. Given that these migrations have been among the most important demographic events of modern times, surprisingly little attention has been paid to the implications for health care.

Perceptions of the subject vary: the host populations, fuelled by reports of a high incidence of tuberculosis among migrants, have been concerned about risks to their own health; for health care providers the principal issue has been the inability of some migrants to speak the language of the host nation; and for migrants the main concern has been the failure, as they see it, of health services to recognise their needs and respond. Perhaps not surprisingly, the limited amount of research carried out largely reflects the concerns of the host population and its health care practitioners, as a recent World Health Organisation publication makes clear. ${ }^{1}$ Most studies have adopted a medical model in which health problems are viewed solely in terms of discrete diseases while the effect of migration is seen in terms of the creation of another social dimension, ethnicity, by which society can conveniently be stratified by epidemiologists. ${ }^{23}$ As a result, research has been oriented to particular "ethnic" diseases, such as rickets, despite the minor importance that many immigrants ascribe to them. ${ }^{4}$ Interestingly the commonest ethnic disease in the United Kingdom-cystic fibrosis-is rarely if ever viewed as such. Of far greater importance to migrants, suggest the contributors to the WHO report, is their doctors' lack of understanding of their culture. Without this, it is claimed, many illnesses are incurable. The report therefore calls for change in three interrelated aspects: the understanding of migrants' health needs; the attitude of health care providers; and the orientation of research.
The health needs of minority ethnic groups differ in degree rather than in kind from those of the indigenous population. Heart disease, cancer, mental illness, and physical disabilities are the major health problems of minority and majority $\stackrel{\varrho}{c}$ ethnic groups alike. Where morbidity and mortality rates are $\widehat{\partial}$ higher in minority groups (though the lack of routinely $\overline{\bar{J}}$ collected data means that little information on this aspect is available) policy makers must recognise the contribution not $\$$ only of poor material circumstances, often exacerbated by 2 discrimination, but also of the harm caused by the social dislocation of migration-uprooting, loss of identity, home- $\stackrel{\vec{f}}{\rightarrow}$ sickness, and the sense of belonging to an underclass.

Apart from being aware of such factors what more can 음 health care providers do? While the availability of interpreters $\frac{\text { s }}{7}$ can help overcome language barriers, cultural barriers will $\stackrel{\mathbb{}}{\circ}$ remain. The importance of cultural differences in illness behaviour, in the presentation of symptoms, and in the $\vec{\circ}$ expectations of consultations has been recognised in psy- $\overrightarrow{\vec{\omega}}$ chiatry. Unfortunately this is not true of other branches of ${ }_{\sigma}^{\omega}$ medicine. Failure to understand cultural differences may lead to frustration and irritation on the part of doctors, as "deviant" patients are referred from one specialist to another of with no benefit. The patients, meanwhile, become increas- os ingly despondent with the failure of Western medicine to $\mathscr{D}_{\infty}$ help restore their health. One effect of this is to confirm the ir importance of folk healers within each ethnic group.

The need to adopt a pluralistic model of formal carers is $ᄋ$ but one requirement of research on this subject. Another is to $\mathrm{Gr}$ acknowledge that many of the health problems peculiar to $\mathbb{D}$ minority ethnic groups result from their encounter with $\frac{\mathbb{D}}{\mathbb{D}}$ another culture, that of the indigenous population. A greater $\bar{z}$ understanding of such encounters, through social science $\stackrel{\mathbb{\perp}}{-}$ research, would benefit both the providers and the users of $\vec{\varphi}$ health services.

While calling for more research into this subject, the $\square$ WHO report is aware of the risks. Given that minority ethnic communities are highly visible in their host societies, great sensitivity is needed as any data produced may be misinterpreted and misused. One possible safeguard is to concern $\stackrel{\mathbb{Q}}{\stackrel{2}{2}}$ members of the community in setting the research agenda. $\overrightarrow{\overrightarrow{0}}$ Even the best intentioned work may backfire, however, and 3 emphasising the importance of culture may lead to doctors ascribing all health problems and incomprehensible behaviour to cultural differences. In addition, recognition of culture can promote a stereotyped image of members of minority groups, who are in reality as heterogenous as $\frac{5}{3}$ members of the majority ethnic group. But there again our knowledge of the latter is slight. ${ }^{56}$

Senior Lecturer in Community Medicine,

London School of Hygiene and Tropical Medicine,

London WCIE 7HT

1 Colledge M, van Guens HA, Svensson P-G, eds. Migration and health: towards an understanding of the health care needs of ethnic minorities. Copenhagen: World Health Organisation Regional Office for $N$ Europe; London: HMSO, 1986.

2 Beevers DG, ed. Ethnic differences in common diseases. Introduction (special issue). Postgrad $\widetilde{ }$ Med f 1981;57:747.

3 Beevers DG, ed. Ethnic differences in common diseases. Introduction (special issue). Postgrad Med f 1983;59:615.

4 Webb P. Health problems of London's Asians ad Afro-Caribbeans. Health Visitor 1981;54:141-7.

5 Blaxter M. Women talking. Soc Sci Med 1983;17:59-69.

6 Cornwell J. Hard-earned lives. London: Tavistock Publications, 1984 